\title{
Changing Etiological Incidence of Acute Pancreatitis in Adults- Single Tertiary Centre Study.
}

\author{
Dr.Mrigendra Kumar Rai
}

\begin{abstract}
Background: Acute pancreatitis is an inflamatory disease of pancreas having mild self limiting course of illness in $80 \%$ to mortality upto $20 \%$ of cases.In developed countries, most common causes of acute pancreatitis are common bile duct stones in 38\% and alcohol abuse in $36 \%$ of cases.

Objective: To study the etiological incidence of acute pancreatitis in adults in tertiary care centre.

Methods: A cross-sectional study was conducted on hundred patients who were admitted with the features of acute pancreatitis in different surgical wards.The diagnosis was made on the basis of detailed history,physical examination, serum amylase and lipase levels and other required investigations.

Result: The commonest factor responsible for acute pancreatitis was found to be alcoholism(58\% cases) followed by biliary calculi(32\%cases).It was more commonly found in males(62\%), in between $30-39$ years of age group $(35 \%)$ and in low socio-economic group (62\%) of patients.

Conclusion: Acute pancreatitis is common among middle aged males of low socio-economic group.Alcoholism is the most common etiological factor.
\end{abstract}

Keywords: Acute pancreatitis, alcoholism,biliary calculi,serum amylase.

\section{Introduction}

Acute pancreatitis is an inflamatory disease of pancreas with a wide spectrum of symptoms ranging from mild self limiting course of illness without serious complications in $80 \%$ of patients to a substantial mortality upto $20 \%$ of Patients ${ }^{[1]}$.It has a wide range of etiological factors, approximatly $80 \%$ cases are associated with biliary calculi or sustained alcohol abuse; the relative frequency of these two factors depends on the prevalence of alcoholism in the population studied ${ }^{[2]}$.In developed countries, most frequent causes of acute pancreatitis are stones in common bile duct in $38 \%$ and alcohol abuse in $36 \%$ of cases ${ }^{[3,4]}$. Gallstone pancreatitis is seen more frequently in women between 50-70 years of age, whereas alcohol-induced panceratitis is more prevalent in young men between $30-45$ years of age ${ }^{[5]}$. Aim of this study was to find out the etiology of acute pancreatitis exclusively in adult patients admitted with the symptoms and signs of acute pancreatitis in the department of surgery at Rajendra Institute of medical sciences, Ranchi.

Material And Methods

This was a cross-sectional study, conducted during the period of November 2014 to October 2016, at Rajendra Institute of Medical Sciences, Ranchi.One hundred patients with the features of acute pancreatitis were selected for the study. Written consent taken from all the patients selected for study. The diagnosis was made on the basis of detailed history,physical examinations,serum amylase and lipase levels,trans-abdominal ultrasonography,CECT of abdomen,MRCP and other required investigations.Conservative approach of treatment was taken and all patients who were treated successfully were followed -up on out-patient basis for the period of four weeks for any complication.

\section{Results}

Out of the 100 patients taken for study, 62 were male(62\%) and 38 were female(38\%). The maximum incidence of acute pancreatitis was found in between 30-39 years of age,i.e 45 patients(45\%) and in low income group, i.e 62 patients $(62 \%)$. The commonest factor responsible for acute pancreatitis was alcoholism in 58 patients $(58 \%)$ followed by biliary calculi in 32 patients(32\%). The most common presenting complains with acute pancreatitis were epigastric pain and nausea/repeated vomitting/retching in all 100 patients(100\%).Hiccough was found in 20 patients(20\%).Among clinical signs, guarding over epigastrium and tachycardia were found in all patients $(100 \%)$.Elevated levels of serum amylase and lipase more than three times were found in 95 patients $(95 \%)$, and levels less than three times but above normal range were found in 5 patients(5\%).

In our study $86 \%$ of cases were managed conservatively without any complication,early operative intervention in $2 \%$ cases for pancreatic necrosis, $8 \%$ cases develop pseudocysts,out of which $4 \%$ cases resolved spontaneously within six weeks period, late operative interventions needed in $4 \%$ cases of non-resolved pseudocysts and there was $4 \%$ mortality. 


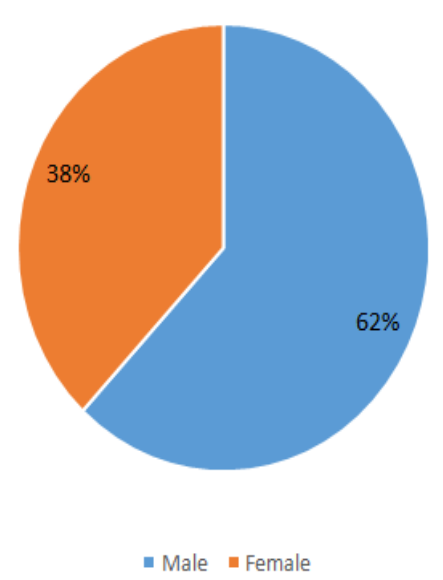

Fig. 1: Gender distribution

Table 1: Age distribution

\begin{tabular}{|c|c|c|}
\hline Age group(in years) & No. of patients & Percentage \\
\hline $20-29$ & 20 & 20 \\
\hline $30-39$ & 45 & $\mathbf{4 5}$ \\
\hline $40-49$ & 25 & 25 \\
\hline $50-59$ & 8 & 8 \\
\hline 60 and above & 2 & 2 \\
\hline
\end{tabular}

Table 2: Socio-economic status

\begin{tabular}{|c|c|c|}
\hline Group & No. Of patients & Percentage \\
\hline Low & 62 & $\mathbf{6 2}$ \\
\hline Middle & 28 & 28 \\
\hline High & 10 & 10 \\
\hline
\end{tabular}

Table 3: Etiological Factors

\begin{tabular}{|l|c|c|}
\hline Factors & No. of patients & Percentage \\
\hline Biliary calculi & 32 & 32 \\
\hline Alcoholism & 58 & $\mathbf{5 8}$ \\
\hline Abdominal trauma & 6 & 6 \\
\hline Pancreatic duct calculi & 2 & 2 \\
\hline Periampulary carcinoma & 2 & 2 \\
\hline
\end{tabular}

Table 4: Frequency of symptoms and signs of acute pancreatitis

\begin{tabular}{|l|c|c|}
\hline \multicolumn{1}{|c|}{ Symptoms } & Frequency & Percentage \\
\hline Epigastric pain & 100 & 100 \\
\hline Nausea/repeated vomitting/retching & 100 & 100 \\
\hline Hiccoughs & 20 & 20 \\
\hline Signs & & \\
\hline Tachycardia & 100 & 100 \\
\hline Tachypnea & 80 & 80 \\
\hline Hypotension & 90 & 90 \\
\hline Guarding over epigastrium & 100 & 100 \\
\hline Distension of abdomen & 70 & 70 \\
\hline Pleural effusion & 30 & 30 \\
\hline
\end{tabular}

\section{Discussion}

Acute pancreatitis,an inflamatory disease of pancreas, having mild self limiting course without any serious complications in $80 \%$ to a mortility upto $20 \%$ of patients ${ }^{[1]}$.Among etiological factors, biliary tract stones or sustantial alcohol abuse are associated with upto $80 \%$ of cases, the relative frequency depends on the prevalence of alcoholism in the population ${ }^{[2]}$.Stones in common bile duct account for $38 \%$ and alcohol abuse for $36 \%$ of cases in developed countries ${ }^{[3,4]}$.In our study, the commonest etiological factor for acute pancreatits is alcoholism $(58 \%)$ followed by biliary tract stone(32\%). This is because of high prevalence alcoholism mostly of crude home made 
alcohol called Hadia(having some ritual importance also) among low socio-economic group of population in this region of India consists of Jharkhand and neighbour districts of West Bengal,Odisha and Chhattisgarh.

Alcohol induced pancreatitis is more common among men ${ }^{[5]}$.In our study also men (62\%) are most commonly affected.The median age of onset of alcohol induced acute pancreatitis is in between third and fourth decades ${ }^{[5]}$.In our study the maximum age incidence is in between 30-39 years(45\%). A three fold or higher level of serum amylase and lipase confirms the diagnosis ${ }^{[6]}$.In our study,95\% of patients have three fold or higher serum level of amylase and lipase.CECT is currently the best diagnostic method for pancreatic necrosis ${ }^{[7]}$.In our study CECT has been done in all patients to exclude pancreatic necrosis in early stage.CT severity index has a good correlation with mortality and morbidity ${ }^{[8]}$.Most episodes of acute pancreatitis $(80 \%)$ are mild and self limiting $^{[9]}$. Organ failure and infection of pancreatic necrosis are important determinants of mortality in patients with acute pancreatitis and the presence of either indicates severe disease ${ }^{[10]}$.In our study $86 \%$ of cases were managed conservatively without any complication,early operative intervention for infection of pancreatic necrosis in $2 \%$, late operative intervention for pseudocyst in $4 \%$ and mortality in $4 \%$ of cases.

\section{References}

[1]. Lund H,Tonnesen MH,Olsen O.Long term recurrence and death rate after acute Pancratitis.Scand J Gastroenterol 2006;41;234-238

[2]. Thomas EC,Stanley WA,Management of acute pancreatitis,Maingot's abdominal Operations, $12^{\text {th }}$ ed.New york:McGraw Hill:2013.

[3]. Lankisch PG,Assamus C,Lehnick D,Maisonneuve P,Lowenfels AB.Acute Pancreatitis;does gender matters?Dig Dis Sci 01;46:2470-2474.

[4]. Spanier BW,Dijkgraaf MG,Bruno MJ.Epidemiology aetiology and outcome of Acute and chronic pancreatitis;An update.Best Prac Res Clin Gastroenterol 2008;22:45-63

[5]. Dudeja V,Christian JD,Jensen EH,Vichers SM.Exocrine Pancreas;Sabiston textbook Of surgery,20 $0^{\text {th }}$ ed.Elsevier:2017.

[6]. Fisher WE,Andersen DK, Windsor JA,Saluja AK,Brunicardi FC.Acute panreatitis. Schwartz's Principles of Surgery, 10 ${ }^{\text {th }}$ ed.New York:MacGraw Hill :2015.

[7]. Pezzilli R,Barakat B,Fabbri D,Imbrogno A,Cavazza M.Pancreatitis:Pathophysiology, Clinical Aspects,Diagnosis e Treatment,Emergency care J Anno VII numero 2, Giugno 2011.

[8]. Bollen TL,Singh VK,Mauerer R.A comparative evaluation of radiological and Clinical scoring system in the early prediction of severity in acute pancreatitis. Am J Gastroenterol,2012;107:612.

[9]. Werner J,Hartwig W,Buchler MW.Management of acute pancreatitis and Complications.Blumgart Surgery of Liver,Biliary Tract,Pancreas, $4^{\text {th }}$ ed.2007.

[10]. Petrov MS,Shanbhag S,WindsorJA.Organ failure and infection of pancreatic Necrosis as determinants of mortality in patients with acute pancreatitis. J Gastroenterol,sept. 2010,vol.139(3),813-820. 